\title{
Matizes do Jazz \\ na música dominicana
}

\section{Paul Austerlitz Álvaro Neder}

(IFRJ)

RESUMO: Este artigo considera a influência do jazz sobre a música da República Dominicana. A dupla significação do jazz como, de um lado, uma forma genericamente estadunidense, e, de outro, uma forma especificamente afroamericana, promove contradições em sua assimilação dominicana. Embora o jazz tenha frequentemente permanecido fora da corrente dominante nos Estados Unidos, representa conexões com os EUA hegemônicos para alguns dominicanos, que o veem como um marcador cosmopolita de prestígio social. Entretanto, inovadores dominicanos como o saxofonista Tavito Vásquez criaram brilhantes híbridos de jazz e merengue que afirmam as bases partilhadas da música de influência africana nos EUA e na República Dominicana.

PALAVRAS-CHAVE: jazz; República Dominicana; etnomusicologia

\section{THE JAZZ TINGE IN DOMINICAN MUSIC}

ABSTRACT: Considers the influence of jazz on music of the Dominican Republic. Jazz's double signification as a generically North American form on one hand and a specifically African-American form on the other fosters contradictions in its Dominican assimilation. While jazz has often stood outside of the dominant mainstream in North America, it represents connections to the hegemonic U.S. to some Dominicans, who see it as a cosmopolitan marker of social status. Dominican innovators such as saxophonist Tavito Vásquez, however, created brilliant merengue-jazz hybrids that affirm the shared foundation of African-influenced music in the U.S. and the Dominican Republic.

KEYWORDS: jazz; Dominican Republic; ethnomusicology 
Desde sua concepção, o jazz desenvolveu-se em diálogo com músicas afro-latinas; Jelly Roll Morton argumentou que os "matizes hispânicos" foram fundamentais para os desenvolvimentos musicais ocorridos na quintessencialmente caribenha cidade de Nova Orleans (Lomax, 1973, p. 63). As duas guerras mundiais do século passado disseminaram a hegemonia estadunidense e suas músicas populares, tendo o jazz se tornado doméstico no mundo inteiro. Fusões especialmente férteis emergiram entre o jazz e outras músicas do Atlântico Negro (ver Averill 1989, Coplan 1985, Pinkney 1989). O jazz latino levantou vôo realmente nos anos 40 sob a influência de inovadores como os afro-cubanos Machito, Mario Bauzá, Chano Pozo e o bebopper Dizzy Gillespie. Gillespie escreveu uma vez sobre sua relação com Pozo: “Uma vez que Chano não falava inglês, as pessoas sempre perguntavam, 'Bom, como vocês se comunicam?' 'Deehee no peek pani, me no peek Angli, bo peek African', respondia Chano [Dizzy no speak Spanish, I no speak English, but we both speak African", ou seja: Dizzy não fala espanhol, eu não falo inglês, mas nós dois falamos africano] (1979, p. 318). Similarmente, Machito disse uma vez que o “casamento" do jazz com "os ritmos da música cubana não era uma união convencional - era um casamento de amor" (em Waxer, 1994, p. 154). Mas as músicas do Atlântico Negro formam uma constelação variegada, não uma paisagem sonora uniforme; como afirma Paul Gilroy, "a raça não traz consigo nenhuma coroa de significados fixos absolutos” (1993a, p. 109). O estudo da música na diáspora africana, portanto, “envolve a luta com uma questão em particular. É o quebra-cabeças de definir qual estatuto analítico deveria ser dado à variação...entre culturas negras que seus hábitos musicais revelam" (Gilroy, 1993b, p. 79-80). Este ensaio considera criticamente a história da música influenciada pelo jazz na República Dominicana, rastreando sua recepção e desenvolvimento estilístico.

Em uma ocasião, numa festa na República Dominicana, o anfitrião apresentou-me a seus outros convidados como um músico que toca el jazz clásico. Pelo tom de sua voz, ficou claro que este cavalheiro tinha o jazz em alta estima. Satisfeito por ser cumprimentado desta maneira e satisfeito por estar na companhia de pessoas que partilhavam minha paixão por música, relatei a meus 
novos amigos sobre uma experiência recente em uma cerimônia vudu realizada durante uma semana no Haiti. O evento havia produzido uma forte impressão em mim, pois havia percebido muitos paralelos estéticos entre o jazz e a música vudu. Pensei que meus amigos estariam interessados nesses vínculos. Estava errado: eles demonstraram ter sido pegos de surpresa, reagindo com agitação e exasperação. Eles não viam o vudu da mesma forma que viam "el jazz clásico". À medida que me tornei mais familiarizado com a República Dominicana, descobri que uma ideologia hispanocêntrica prevalece ali lado a lado com muitas influências africanas vitais, resultando em um caso agudo de "ambivalência socializada" em relação à questão racial (Herskovits, 1937, p. 295-960).

\section{Merengue e Jazz no início do século vinte}

A população da República Dominicana constitui-se estimativamente de 80 por cento de mestiçagem africana-europeia, 15 por cento negros e 5 por cento brancos; o sociólogo dominicano Pérez Cabral adequadamente chama seu país de "comunidad mulata" (Pérez Cabral, 1967, p. 75). O elemento africano neste mix é crucial; como atesta Martha Ellen Davis, a mais destacada entre os etnomusicólogos dominicanistas, a República “sem dúvida, deveria ser considerada uma nação afro-americana - isto é, uma nação do Novo Mundo na qual a influência cultural africana figura de maneira proeminente, senão predominante" (Davis, 1976, p. 2). Santo Domingo foi uma colônia espanhola fundada em 1493 por Colombo. Seu terço ocidental foi cedido à França em 1697 e o Haiti foi fundado lá em 1804 como resultado de um levante escravo bem sucedido. Os haitianos entraram na parte oriental da ilha em 1822, expulsando os espanhóis e abolindo a escravidão. A classe dominante dominicana, de compleição tendente à branca, viu desfavoravelmente esta “ocupação haitiana" e trabalhou para expulsar os haitianos. Eles tiveram sucesso e a República Dominicana obteve sua independência em 1844. É significante que a República Dominicana tenha obtido sua independência do Haiti e não da Espanha: desde 
1844, a classe governante dominicana tem propagado uma noção eurocêntrica de identidade nacional.

Depois da retirada da Espanha como força imperial e a ascensão dos EUA como potência mundial, os dominicanos tornaram-se antagônicos em relação à intervenção estadunidense mas foram também atraídos pela riqueza e modernidade ianques. A ambivalência dominicana assumiu uma segunda existência à medida que a dominação neocolonial estadunidense do país se consolidou. Realmente, como demonstrou Frantz Fanon, a ambivalência é inerente à mentalidade colonial (Fanon, 1967, p. 83). Como temos visto, entretanto, sentimentos complexos engendram uma criatividade multifacetada. Os principais determinantes das adaptações dominicanas do jazz são a conexão que os músicos dominicanos sentem com o jazz como resultado, por um lado, do compartilhamento de estéticas afro-derivadas e, por outro lado, da negociação de sentimentos contraditórios resultantes de atitudes neocoloniais.

A música da República Dominicana reflete a etnicidade afro-hispânica do país. Formas neoafricanas, indispensáveis a cerimônias religiosas rurais, predominam. Estas incluem música ritual afro-dominicana das organizações fraternais religiosas como palos e congo e uma forma processional celebratória chamada gagá, que ocorre durante a Semana Santa católica e consiste de uma melodia em hoquetos distribuída entre vários trompetes e acompanhada por percussão². Menos prevalente do que estas formas neoafricanas, músicas europeias tais como preces cantadas chamadas salves sagradas são também significantes na paisagem sonora. Situado entre os extremos das influências africanas e europeias há um grande repertório de músicas sincréticas tais como mangulina, bachata e merengue ${ }^{3}$.

Datando da metade do século 19, as primeiras referências ao merengue o descrevem como uma música de dança de salão relacionada à danza pan-

\footnotetext{
${ }^{1} \mathrm{O}$ palos e o congo dominicanos estão à parte da dança cubana conga e da religião Palos, embora sejam similares a estas.

${ }^{2}$ Ver a gravação Various artists.

${ }^{3}$ Ver Omitido 1997, Davis 1976 e 1981, Fernández e Sánchez 1997, e Pacini Hernandez 1995.
} 
caribenha, que se desenvolveu da elitizada contredanse europeia. O merengue distinguiu-se pelo fato de que era dançado por pares independentes (em vez de em grupos) e por influências afro-caribenhas na música bem como por um movimento ondulante dos quadris. Depois de um curto período de modismo nos salões de dança dominicanos, foi rejeitado pelas elites eurocêntricas devido ao seu estilo de dança, que foi considerado vulgar, e por causa de seus elementos musicais de influência africana. A maioria dominicana rural, entretanto, adotou o merengue, nele introduzindo ainda mais influências africanas. Variantes do merengue com diversas instrumentações se desenvolveram em várias áreas da República Dominicana, mas apenas a versão da região de Cibao ganhou destaque. Por volta do início do século 20, o merengue típico cibaeño (merengue folclórico estilo Cibao), executado com tambora (um tambor com duas peles), güira (instrumento de metal executado por atrito), acordeão de botões e saxofone alto era a mais popular dança social na região rural de Cibao e em seus barrios (bairros urbanos pobres).

No merengue, o estilo do acordeão e do saxofone é baseado em ostinati (ou riffs repetidos) chamados jaleos, que se misturam com os ritmos da tambora, güira e dança em uma estética de influência africana típica. Além de executar jaleos, os primeiros saxofonistas do merengue improvisavam linhas retorcidas em contraponto com o acordeão e a tambora. Como relatou a mim um nativo do Cibao que dançou em muitas fiestas de merengue durante o início do século 20 , os saxofonistas "costumavam ornamentar e tocar montes de escalas e coisas bonitas: muito bonito. Seu acompanhamento ia para cima e para baixo . . . ele saía do merengue mas permanecia dentro do ritmo" 4 . A similaridade deste estilo de tocar saxofone com a improvisação do jazz coloca a questão de uma possível influência jazzística sobre o merengue inicial, mas os grupos de merengue incorporaram saxofones antes do período da influência dos EUA na República Dominicana. Instrumentos de sopro estavam presentes no merengue rural já no

\footnotetext{
${ }^{4}$ Entrevista com Pichardo. Este estilo de execução de saxofone pode ser escutado no CD Omitido 1997a.
} 
século 19 e o saxofone havia se fixado na música por volta de 1910 (Hoetink, 1982, p. 206, Rodríguez-Demorizi, 1971, p. 87, Pichardo n.d.b.).

O vínculo estético entre o merengue em seus primórdios e o jazz, portanto, resulta de ingredientes musicais compartilhados e não de influências estadunidenses; as duas músicas desenvolveram-se por meio da união de sensibilidades africanas e europeias. O folclorista e compositor dominicano Estéban Peña-Morell certa vez inverteu a questão de uma possível influência jazzística sobre o merengue antigo ao perguntar divertidamente "o jazz se originou em Santo Domingo?" (Anônimo 1931).

Um olhar mais de perto sobre a história estilística do merengue antigo ilustrará o caminho que a mistura de sensibilidades africanas e europeias seguiu na República Dominicana. Emulando orquestas de salão, que apresentavam instrumentos de sopro, músicos de barrio de merengue incorporavam ocasionalmente um bombardino em seus grupos. De acordo com músicos de Cibao que estiveram em atividade durante o início do século 20, o saxofone alto foi usado inicialmente no merengue apenas em ocasiões em que um executante de bombardino não se encontrava disponível (Alberti 1975, p. 87). O compositor dominicano Julio Alberto Hernández se lembra que executantes de bombardino injetaram matizes de sabor local, afro-caribenho na nobre danza, de origem europeia: “O bombardino desempenhava um papel especial [na danza]. Realizava um acompanhamento rítmico... Eles improvisavam ritmos típicos (folclóricos), ritmos tropicais, que tinham um certo caráter... Havia alguns excelentes executantes de bombardino, com embocaduras especiais. Frequentemente as pessoas prestavam atenção ao bombardino em vez de dançar". ${ }^{5}$

A execução do saxofone no merengue antigo era, portanto, baseada no estilo do bombardino. O saxofonista Antonio Lora, que estava em atividade no início do século 20, explica que uma abordagem mais adequada às texturas percussivas da tambora e do acordeão logo emergiu: "o saxofone era o melhor instrumento .. . para a música típica. O bombardino soava terrível; soava como

\footnotetext{
${ }^{5}$ Entrevista com Hernández.
} 
um trombone. O saxofone . . . complementava melhor o acordeão"6. Hernández acrescenta que o "acompanhamento do saxofone veio da danza. Mas uma vez que saxofones são mais flexíveis que bombardinos . . . bem, eles tocavam montes de variações e piruetas, para cima e para baixo"7. Pedro "Cacú" Lora e Avelino Vásquez foram os primeiros saxofonistas a tocar merengue regularmente e os arquitetos do estilo original do saxofone no merengue.

A República Dominicana sofreu severas dificuldades econômicas no início do século 20 e seus credores europeus ameaçaram enviar navios de guerra para cobrar dívidas não pagas. O presidente Wilson, dos EUA, considerou inaceitável a possibilidade de uma presença militar europeia no Caribe e, evocando o Corolário de Roosevelt à Doutrina Monroe (que conclamou os EUA a oporem-se à presença colonial europeia na América Latina), ordenou uma invasão estadunidense da República Dominicana em 05/05/1916. No ano seguinte, os Marines estabeleceram um governo militar que governou o país até 1924. Os dominicanos não ficaram de braços cruzados frente à ocupação estadunidense: populações rurais desencadearam uma guerra de guerrilha, enquanto as elites urbanas montaram um programa internacional de protesto na frente diplomática. Este programa foi bem sucedido: ele eventualmente forçou os EUA a “abandonar a ocupação" (Calder, 1984, p. 241). Associado à campanha diplomática, o clima de nacionalismo cultural fomentou o culto de tudo o que fosse dominicano.

Ao mesmo tempo, entretanto, muitos dominicanos foram atraídos pela cultura popular estadunidense que os Marines haviam trazido. Estas tendências em competição estavam no centro das repercussões musicais da ocupação. No início da ocupação, as elites dominicanas possuíam gostos europeus em música, rejeitando tanto a música afro-caribenha local e rústica quanto as importações modernísticas estadunidenses em favor da valsa, polca, danza e o danzón cubano. O espírito de resistência, entretanto, com certeza exerceu o papel de inspirar compositores da cidade de Santiago de los Caballeros, na região de Cibao, a escrever música erudita nacionalista romântica baseada no merengue e outras

\footnotetext{
${ }^{6}$ Entrevista com Lora.

${ }^{7}$ Entrevista com Hernández.
} 
formas locais. Influenciado por esta tendência, o líder da mais importante banda de danças de Cibao, Juan Espínola, ganhou fama por executar refinados arranjos de merengue, reminiscentes do estilo danza, para dança de salão (Incháustegui, 1974).

Em 1921, Juan Pablo "Pavín” Tolentino fundou a Orquesta Bohemia, que em breve tiraria o lugar do grupo de Espínola como a primeira orquestra de salão de Cibao. Como Espínola, Tolentino começou especializando-se no danzón cubano, que demandava duas clarinetas, corneta, bombardino, baixo acústico e percussão. A crescente popularidade da música estadunidense, entretanto, manifestou-se na mudança de instrumentação do grupo: em uma década, a Orquesta Bohemia havia se tornado uma jazz band consistindo de três saxofones (ou clarinetas), corneta, violino, bombardino, tuba, banjo, bateria e percussão ${ }^{8}$. 0 pianista Luis Alberti trouxe um novo grupo à cena em 1928 e, com a onda da música estadunidense em plena força, ele o chamou Jazz Band-Alberti. A Orquesta Bohemia e o grupo de Alberti competiram pela posição de representantes das mais autênticas vozes do jazz da cidade; quando a Orquesta Bohemia acrescentou um banjo, Alberti teve que ter um também (Alberti, 1975. p. 30).

Como se pode imaginar, a onda do jazz não encontrou uma reação inteiramente favorável em face do sentimento anti-ianque que predominou como resultado da ocupação: em certo momento, os músicos chegaram a boicotar a execução de música estadunidense. Em 1933, Alberti teve a ideia original de tirar proveito da popularidade do jazz executando merengues com instrumentação de big band. Tolentino fez o mesmo logo em seguida, reforçando sua banda regular com um grupo típico de merengue que consistia de acordeão, tambora e güira (Incháustegui, 1973). A tambora, a güira e o acordeão foram permanentemente incorporados nas bandas de Alberti e Tolentino ${ }^{10}$, e o merengue logo encontrou

\footnotetext{
${ }^{8}$ Entrevista com Tolentino.

9 Mais tarde, este grupo chamou-se, sucessivamente, Orquesta Lira de Yaque, Orquesta Presidente Trujillo, Orquesta Generalísimo Trujillo e Orquesta Santa Cecilia.

${ }^{10}$ Estas orquestas usaram acordeões em vez dos harmonicamente limitados acordeões de botão utilizados no merengue típico.
} 
um lugar permanente, embora pequeno, nos repertórios das bandas de dança de Cibao. Desenvolveu-se uma prática de finalizar cada baile com um merengue ${ }^{11}$. Foi precisamente a experiência neocolonial que despertou o interesse das elites de Cibao no merengue; antes da ocupação eles haviam rejeitado as formas locais.

Alguns dos parentes mais jovens do pioneiro do saxofone típico Avelino Vásquez que vinham tocando na Orquesta Bohemia formaram seu próprio grupo em 1932. A Orquesta los Hermanos Vásquez logo se tornou a orquestra de danças número um da região, e permaneceu popular até o fim dos anos 40. A rua onde viviam muitos dos Vásquez e onde a orquestra ensaiava se tornou conhecida como "La Calle Alegría” ("Rua Alegria”), porque os ensaios da orquestra eram tão divertidos que as pessoas se juntavam ali para ouvir e dançar. A Orquesta los Hermanos Vásquez incluía vários excelentes saxofonistas, que conduziam experiências inovadoras ao aplicar jaleos de acordeão estilo merengue à seção de saxofones da jazz band. O compositor Hernández escreveu isto a respeito do papel da atividade musical em La Calle Alegría no desenvolvimento do estilo de saxofone do merengue:

O papel do saxofone no merengue adquiriu suas características tradicionais graças às contribuições dos celebrados músicos populares de Santiago [de los Caballeros], tais como Pedro "Cacú" e a família Vásquez, que converteram a ruela conhecida como "Rua Alegria" em uma intensa prospecção de elocubrações saxofonísticas que serviram de modelo para a moderna orquestração de nossa dança típica ${ }^{12}$.

A fusão da essência do merengue, jaleos de saxofone, com o jazz estava no coração do vínculo simultâneo da música com a cultura local e cosmopolita. Estava também no coração da qualidade dançante da música.

Entrementes, habitantes dos barrios continuaram a dançar o merengue baseado no acordeão. Dois tipos de merengue típico cibaeño eram prevalentes no início do século vinte: uma forma secional com partes denominadas paseo,

\footnotetext{
${ }^{11}$ Alberti, 1975, p. 29, entrevista com Tolentino.

12 Hernández, 1969, p. 61.
} 
merengue e jaleo e uma forma de uma parte apenas chamada pambiche ${ }^{13}$. Embora seja provável que ambas já existissem antes da ocupação por parte dos EUA, frequentemente se diz que o pambiche se originou durante este período. Conforme esta versão, os Marines estadunidenses algumas vezes iam a fiestas locais mas não sabiam dançar o merengue corretamente, terminando por misturar passos do fox-trot com os do merengue. Imitando os estadunidenses, os dominicanos da cidade de Puerto Plata criaram um passo de dança chamado merengue estilo yanqui, que era acompanhado por um ritmo sincopado de tambora. A nova dança tornou-se associada a uma canção sobre um tecido chamado "Palm-Beach" (ver a gravação Omitido, 1997).

Palm-Beach es mejor que dril,

$Y$ es mejor que el casmir.

Con él yo voy a fiestar,

Y con mi novia a bailar. ${ }^{14}$

Palm-Beach é melhor do que drill,

E é melhor que cashmere;

Com ele vou festar,

E com minha namorada dançar.

O novo estilo teria passado a se chamar pambiche, uma dominicanização do anglicismo "Palm Beach": assim como o tecido Palm Beach não era nem cashmere nem drill, o pambiche não era nem foxtrote nem merengue. A estória sobre a origem do pambiche inverte as relações de poder da era da ocupação: os dominicanos tiveram dificuldades em se haver com o poderio militar estadunidense, mas sua superioridade na pista de dança era inquestionada, e eles

\footnotetext{
${ }^{13}$ Estes dois tipos continuam sendo executados hoje, embora na atualidade o paseo seja usualmente retirado da forma secional. Ver a gravação OMITIDO 1997.

${ }^{14}$ Alberti, 1971, p. 79.
} 
até mesmo criaram um novo gênero a partir da inabilidade coreográfica dos Marines! ${ }^{15}$

\section{Eurofilia e Merengue-Jazz}

O ditador dominicano Rafael Trujillo ascendeu ao poder em 1930. A despeito do fato de que ele próprio era de origem mestiça africana e europeia e a despeito do fato de que sua própria avó era de ascendência haitiana, Trujillo abraçou uma ideia racista de dominicanidade que excluiu vínculos explícitos com a África e o Haiti da cultura nacional sancionada oficialmente. As atitudes de Trujillo sobre as influências africanas e haitianas na República Dominicana revelam contradições que são básicas na cultura dominicana. Trujillo perseguiu haitianos, mas era, ele mesmo, de ascendência parcialmente haitiana. Ele instituiu uma lei que baniu práticas mágico-religiosas derivadas da cultura africana tais como o vudu, mas era conhecido por praticá-las ele mesmo. Mesmo hoje, tais práticas mágico-religiosas são raramente discutidas na República Dominicana a despeito de sua ubiquidade. O extremismo do anti-haitianismo de Trujillo foi epitomizado em seu massacre de 1937 de talvez mil e duzentos (ou mais) haitianos residentes na República Dominicana ${ }^{16}$.

A despeito da disseminada antipatia à sua ditadura brutal, Trujillo, como outros nacionalistas populistas, possuía o que um observador denominou "um domínio seguro daquelas áreas sensíveis da psicologia nacional” (Crassweiler, 1966, p. 78): ele sabia como motivar as massas através do uso de "cor, drama e espetáculo" (Crassweiler, 1966, p. 358). Trujillo apresentava-se com fardamento militar completo, frequentemente complementado por ornamentados chapéus

\footnotetext{
${ }^{15}$ Esta estória é ainda frequentemente contada, talvez porque a República Dominicana seja ainda sujeita a uma dominação neocolonial por parte dos Estados Unidos (os EUA ocuparam a República Dominicana novamente em 1965 e continuam a exercer uma influência de bastidores na política dominicana). Como foi mencionado, o pambiche ainda é executado hoje como uma forma musical, mas a dança merengue estilo yanqui caiu em desuso, sendo que não consegui encontrar qualquer informação específica a respeito de sua coreografia.

${ }^{16}$ Estimativas do número variam de mil e duzentos a quarenta mil.
} 
com penas de avestruz (similares aos usados por Marcus Garvey), em ocasiões formais. Ele compreendeu que a cultura popular pode ser um potente símbolo da nação-estado. Havia muito tempo que era ávido praticante de danças sociais, e determinou que o merengue cibaeño deveria tornar-se uma música nacional. Em 1936. Trujillo trouxe a orquestra de Luis Alberti, renomeada Orquesta Presidente Trujillo, de Santiago para a capital para executar arranjos de merengue no estilo big band em bailes da alta sociedade. Todas as orquestras de dança do país foram convocadas a executar merengues de composição recente em louvor ao ditador, e o merengue se tornou um item obrigatório das transmissões de rádio. Para manter-se de acordo com a linha do partido, pesquisadores afirmavam que "a música folclórica dominicana não pode derivar senão da música espanhola" (Nolasco in Davis, 1976, p. 22), e Luis Alberti opinou que o "merengue nada tem a ver com ritmos negros ou africanos" (Alberti, 1975, p. 71).

Ao lado de Luis Alberti, o maior expoente do "merengue tradicional", como o merengue de big band influenciado pelo jazz foi mais tarde chamado, foi a Super Orquesta San José, destacando Joseito Mateo (o "Rei do Merengue") nos vocais ${ }^{17}$. Mateo descreve a impressão que a inovadora fusão de Luis Alberti, de merengue rústico e elaborado jazz de big band, causou nos músicos jovens:

Luis Alberti ascendeu diretamente à alta sociedade, porque era uma orquestra de elite, patrocinada por Trujillo. Trujillo fez com que eles tocassem nos salões e quando os vimos pela primeira vez eles estavam ótimos. Além disso, ele era um grande músico. Esta era outra classe de merengue; os músicos tocavam melhor. Isto é, eles respeitavam convenções musicais . . . tais como crescendos, mordentes, moderato; tudo que a música [clássica] possui. Eles fizeram isso e o resultado soou muito bonito ${ }^{18}$.

As influências do jazz sobre o novo merengue apenas intensificaram sua associação com a sofisticação cosmopolita, aumentando sua desejada distância em relação à cultura afro-dominicana.

\footnotetext{
${ }^{17}$ Ver a gravação Omitido 1997.

${ }^{18}$ Entrevista com Mateo.
} 
Trujillo patrocinou uma estação de rádio chamada La Voz Dominicana, que se especializava em execuções de música ao vivo. Durante os anos 50, a estação empregava mais de dez grupos musicais, incluindo várias orquestras de dança de música latina influenciadas pelo jazz, grupos de merengue típico, uma orquestra sinfônica e grupos especializados em música mariachi mexicana, tango argentino e calipso de Trinidad. O trompetista Hector de Leon foi reconhecido como o líder dos músicos de jazz de La Voz Dominicana; como se lembra um colega, ele "foi aquele que influenciou aquela geração de músicos [dominicanos] a entrarem no jazz"19. De Leon havia conseguido exposição para a música enquanto trabalhava na Venezuela ${ }^{20}$ e desenvolvia um estilo de arranjo influenciado por Stan Kenton. West Coast, ou "cool” jazz, era mais bem conhecido na República Dominicana do que o hard bop da Costa Leste, provavelmente porque aquelas gravações estivessem mais prontamente disponíveis; artistas como Chet Baker e Al Cohn eram populares entre os músicos locais (Solano, 1992, p. 105). O irmão de Hector de Leon, saxofonista alto Choco de Leon, foi também um músico adepto do jazz, tendo sido especialmente influenciado por Art Pepper. ${ }^{21}$ Ele é lembrado pela gravação de versões instrumentais brilhantes de merengues tradicionais com extensos solos influenciados pelo jazz que permanecem como modelos para as fusões merengue-jazz de hoje. ${ }^{22}$ Por volta dos anos 50, arranjos de merengue para big band frequentemente incluíam solos improvisados, o mais das vezes executados por um trompete apoiado pela seção de saxofones tocando jaleos.

Em adição ao jazz, outras músicas estrangeiras ganharam popularidade nos anos 50 e todo tipo de fusões foram feitos. Quando rancheras mexicanas e sambas brasileiros se tornaram populares, orquestras dominicanas gravaram versões em merengue dos sucessos estrangeiros. Uma fusão especialmente bem sucedida deste tipo foi criada pelo jovem arranjador Félix del Rosario. Sua versão

\footnotetext{
${ }^{19}$ Entrevista com Rivera / OMITIDO.

${ }^{20}$ Entrevista com Rivera / OMITIDO.

${ }^{21}$ Outros músicos de jazz respeitados foram o pianista Guillo Carias e o saxofonista Betico Payan, que tocava em um estilo influenciado por Stan Getz (Entrevista com Rivera / OMITIDO).

22 Ver a gravação de Leon, 1981.
} 
merengue de "Skokiaan", uma canção do Zimbábue que havia sido popularizada mundialmente por Louis Armstrong sob o título de "Happy Africa"23, combinava elementos de música do sul da África, big band jazz e merengue. O arranjo começa com ritmos típicos de tambora e güira de merengue, inseridos em uma progressão de acordes I - IV - I - V, característica do sul da África, em vez da progressão V - I, típica do merengue. Esta progressão continua através de todo o arranjo. Executada por um solista no saxofone alto, a melodia exibe glissandos similares àqueles tocados por clarinetistas de Nova Orleans e estilistas do saxofone alto como Johnny Hodges. O chamado e resposta entre as seções de metais e madeiras evoca efeitos similares aos da big band jazz (ver Figura 1).

Figura 1

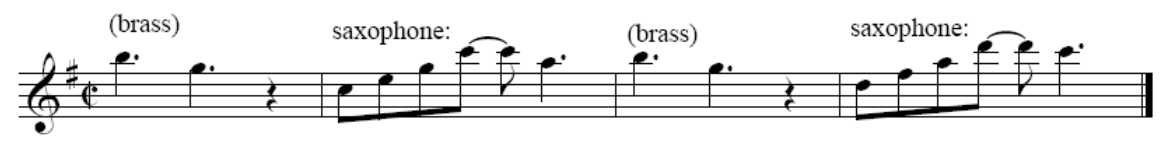

Delineando sucessões em tempo fraco de arpejos diatônicos em um ritmo semelhante à clave afro-cubana (e pan-caribenha), o riff ou jaleo (Figura 2) é frequentemente usado no merengue centrado no acordeão.

Figura 2

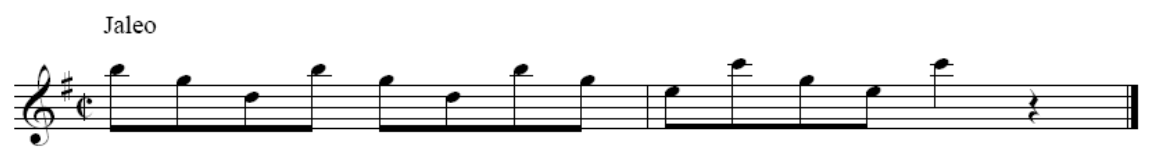

Embora os elementos africanos, jazzísticos e do merengue permaneçam reconhecíveis no arranjo, sua estética compartilhada afro-diaspórica forma uma

${ }^{23}$ Na África do Sul, a palavra "Skokiaan" se refere a bebidas ilícitas que eram vendidas em aldeias (Turino, 2000, p. 141). 
união perfeitamente integrada. O fato de que a "Skokiaan" original era uma tsaba, que David Coplan define como um "estilo sincrético de música urbana [sul-] africana que mistura melodias e ritmos africanos, swing estadunidense e música latino-americana” (Coplan, 1989, p. 270, 154), reforça a amplitude da fertilização cruzada que estava ocorrendo. A gravação de "Skokiaan" de Félix del Rosario demonstra que ao tempo em que o ditador Trujillo denegava as fontes africanas do merengue, os músicos dominicanos estavam conectados aos vínculos com a paisagem sonora diaspórica; como escreve Turino, “'Skokiaan', portanto, exemplifica a natureza emergente e sintética do cosmopolitanismo e do jazz como um gênero cosmopolita de maneira particularmente clara" (Turino, 2000, p. 141).

O mais importante inovador do jazz dominicano, saxofonista alto Tavito Vásquez, também ascendeu ao destaque nos anos $50^{24}$. Sobrinho do pioneiro do merengue típico Avelino Vásquez, Tavito começou a tocar profissionalmente em 1940 com a Orquesta Hermanos Vásquez, de Santiago. Tavito Vásquez estudou saxofone soprano, alto e clarineta, e tocou música estadunidense ("fox trot, boogie-woogie") e música clássica além de formas cubanas e merengue ${ }^{25}$. Vásquez se mudou para a capital para trabalhar em La Voz Dominicana em 1947. Lá, Vásquez tocou na Super Orquesta San Jose e dirigiu sua própria big band (chamada Orquesta Angelita) e quarteto de merengue típico (chamado Conjunto Alma Criolla). Até esta época, os elementos de jazz no merengue haviam pertencido à instrumentação e arranjos. Como afirma Vásquez, sua inovação foi introduzir extensas improvisações jazzísticas no merengue centralizado no acordeão e na big band: "Eu revolucionei o merengue; essa coisa de improvisação [jazzística] no merengue, eu fui o primeiro a fazê-lo”. Ele acrescenta que isto foi “nos anos 40, durante a mesma década em que Charlie Parker revolucionou o jazz . . Os anos 40 foram a década das revoluções musicais"26. Criado em um ambiente de merengue típico e agraciado com um sofisticado ouvido para

\footnotetext{
${ }^{24}$ Ver a gravação Vásquez [sem data] e Omitido 1997.

${ }^{25}$ Entrevista com Vásquez.

26 Vásquez em um programa gravado em videotape de um programa de televisão dominicana; informações mais detalhadas sobre a fonte não estão disponíveis.
} 
harmonias jazzísticas, Vásquez estava em uma posição única para levar a fusão de músicas dominicanas e estadunidenses a novos vôos; seus solos evidenciam um amálgama integrado de sensibilidades afro-latinas e de bebop. Além de fazer dele um inovador da música dominicana, o som emotivo de Vásquez, seu inventivo senso harmônico e linhas originais fazem dele um mestre do jazz por qualquer critério empregado. O LP Tavito Vásquez y su Merengue-Jazz apresenta um repertório de "standards" de merengue rearmonizados por Vásquez com matizes de jazz e executados por um grupo que consistia de saxofone alto, piano, baixo, tambora e güira. ${ }^{27}$

\section{Novas tendências}

Depois que Trujillo foi assassinado em 1961, a República Dominicana abriu-se para influências de fora como nunca antes. O bandleader Johnny Ventura e o arranjador Luis Pérez incorporaram elementos de salsa e de rock'n roll em um merengue exuberante e mais rápido que abandonou a instrumentação de jazz band em favor de um formato menor, de conjunto. Uma emigração massiva ocorreu nas décadas que se seguiram e estima-se que, por volta de 1990, 900.000 dominicanos - 12 por cento da população do país - estavam vivendo apenas na cidade de Nova York. O crescente intercurso transnacional refletiu-se na contínua assimilação, por parte do merengue, de influências externas que vão da "discothèque" e rap a fontes haitianas e sul-americanas. O acesso aos mercados transnacionais para música latina propiciou ao merengue públicos novos e nãodominicanos, o que usurpou a posição da salsa como o mais pedido tipo de dança no Caribe Latino ao fim dos anos 70. A banda do trompetista Wilfrido Vargas liderou a "internacionalização do merengue", como os dominicanos chamaram o boom da música.

O compositor, arranjador e cantor Juan Luis Guerra emergiu como o mais inovador bandleader do merengue nos anos 80 e 90. Depois de estudar jazz no

${ }^{27}$ CD Vásquez [sem data]. 
Berklee College of Music de Boston, Guerra tornou-se influenciado pelo quarteto vocal Manhattan Transfer e formou seu próprio quarteto vocal em 1984. O nome do grupo, 4,40, reflete a estética acadêmica de Guerra: sua música deve ser cantada perfeitamente afinada pela nota do diapasão de concerto da música euroclássica, lá a 440 ciclos por segundo (Tejeda 1993, p. 114). A música de Guerra combina merengue com jazz e funk, incluindo também toques de baladas pop latino-americanas e uma miscelânea de outras músicas como soucous e flamenco:

Nossa principal influência é, mais do que qualquer coisa, o jazz . . . Próximo a este, ou juntamente com ele, está o funk, [especialmente nos] ritmos de trompete, [que são combinados] com os jaleos de saxofone. Temos uma mistura inacreditável: saxofone de merengue e trompetes de funk. Um som de funk como o da Tower of Power com um ritmo extremamente dominicano ${ }^{28}$.

Como revela sua declaração, o jazz estava próximo ao coração de Guerra. Seu primeiro LP, "Soplando", consiste de arranjos vocais influenciados pelo jazz em ritmos de merengue, salsa e samba, e destaca os solos de saxofone ("soprando") por Tavito Vásquez ${ }^{29}$. A qualidade inovadora deste álbum não atraiu o mercado dominicano, e Guerra logo começou a gravar em um idioma mais dançável, mas a alta qualidade de sua música não diminuiu.

Apesar da crescente urbanização e modernização, o merengue centrado no acordeão permaneceu vital nos anos 70, 80 e 90. Enquanto os grupos rurais e aqueles que tocavam para turistas permaneceram dedicados ao estilo tradicional, os grupos do lugar de nascimento do merengue, Santiago de los Caballeros, desenvolveram uma nova forma de merengue típico que acrescentou a conga e o baixo elétrico à formação tradicional de acordeão, saxofone, tambora e güira. Estes grupos se tornaram mais e mais populares durante o boom do merengue, e hoje eles tocam juntamente com as melhores bandas de merengue em luxuosas casas noturnas por toda a República Dominicana e nas comunidades dominicanas

\footnotetext{
${ }^{28}$ Entrevista com Guerra.

29 Este álbum foi lançado posteriormente sob o nome El Original 4:40 (Guerra [1984] 1991).
} 
no exterior. Devido à sua vinculação tanto com a tradição quanto com a modernidade, é adequado chamar esta música de merengue típico moderno ("merengue folclórico moderno").

Tavito Vásquez frequentemente deu canjas em grupos de típico moderno, especialmente aquelas lideradas pelos acordeonistas Rafaelito Román e El Ciego de Nagua ("O Cego de Nagua”, Bartólo Alvarado). A impecável sensibilidade bebop de Vásquez, interpenetrada pelos jaleos trocados pelo acordeão, resultaram em performances de tirar o fôlego que, lamentavelmente, nunca foram gravadas adequadamente $^{30}$. Embora não tenham a formação jazzística de Vásquez, saxofonistas do merengue típico moderno executam solos inspirados que freqüentemente evidenciam características relacionadas ao jazz. O merengue contemporâneo centrado no acordeão exala uma exuberância indômita que levou o New York Times a chamar-lhe um "festival improvisacional avant-garde sob disfarce caribenho" (McLean, 1991, p. 28). Os mais importantes saxofonistas neste idioma são José el Calbo (anteriormente com El Ciego de Nagua líder de seu próprio grupo, La Artilería) e Oscar Peña (do grupo de Francisco Ulloa). A intensidade e energia da composição de Chachí Vásquez "Los Saxofones", executada em um andamento extremamente rápido, privilegiam ritmo e textura, em vez da harmonia estática tônica/dominante, como determinantes da escolha improvisacional. Depois de uma ascensão cromática inicial, Peña toca um arpejo descendente de C maior sobre uma harmonia em D7, efetuando uma situação politonal. Continua então com uma série de escalas e arpejos diatônicos similares àqueles que Tavito Vásquez frequentemente empregava. Mas, em contraste com a abordagem precisa e estudada de Vásquez, Peña toca com indômito abandono, manipulando o timbre do saxofone para criar uma textura em vez de uma melodia, o que não pode ser representado adequadamente em notação convencional. O solo termina com um gesto que contrasta a tessitura grave do instrumento com uma nota extremamente alta, muito acima do que é considerada a tessitura "legítima" do saxofone. Este tipo de execução traz à mente a música do

\footnotetext{
${ }^{30}$ Existem gravações em cassete feitas em sistemas de som de casas noturnas.
} 
saxofonista de free jazz Albert Ayler. Ayler frequentemente começava suas peças com melodias simples e então manipulava os harmônicos do instrumento, criando texturas gritadas ao invés de melodias. Não é provável que Peña e Ayler tenham se influenciado mutuamente de maneira direta, mas eles partilham uma estética derivada da África na qual o uso do growl ("rosnado") e outras manipulações de timbres vocais e instrumentais é central. Milford Graves, que tocou freqüentemente com Albert Ayler nos anos 60, disse uma vez que ele e Ayler não consideravam sua música um "novo lance" (como o "free jazz" era chamado na época), mas, em vez disso, uma expressão que reclama as raízes da cultura afroamericana.

A importância do saxofone no merengue pode estar por trás do fato de que vários dos principais expoentes do jazz dominicano são saxofonistas. Seguindo a tradição de Tavito Vásquez, Félix del Rosario e Choco de León, os saxofonistas dominicanos Crispín Fernández, Juan Colón, Carlito Estrada e Mario Rivera emergiram como inovadores de primeira grandeza no jazz dominicano. Crispín Fernández, o primeiro saxofonista lembrado para sessões de gravação de merengue, lidera um grupo de merengue-jazz chamado Licuado, que destaca Julito Figueroa na tambora e conga. ${ }^{31}$ Juan Colón trabalhou primariamente com o merengue pop; ele já era há muito tempo o saxofonista regular de Juan Luis Guerra. Colón completou um ambicioso projeto concebido em honra de Tavito Vásquez, transcrevendo as improvisações de Vásquez, harmonizando-as para quatro saxofones e gravando-as em arranjos que são entremeados por solos improvisados.

Nos anos 80 e 90 formou-se em Santiago de los Caballeros uma seleção de músicos de jazz que demonstravam uma extraordinária dedicação ao jazz a despeito da escassez de oportunidades de apresentação. O mais notável entre estes é o pianista-bandleader Rafelito Mirabal, cuja música evidencia a influência

\footnotetext{
${ }^{31}$ O pianista / compositor Dario Estrella vem também conduzindo ousados experimentos no jazz dominicano. Depois de tocar na República Dominicana na juventude, Estrella mudouse para Porto Rico e Nova York, tocando e compondo com grandes nomes do jazz latino, tais como Mario Bauzá e Tito Puente. Ele escreve composições idiossincráticas para grupos pequenos, que exibem uma mistura de funk, bebop e free jazz com merengue e outras formas dominicanas, tais como mangulina e salve.
} 
de Pat Metheny. Mirabal também aventurou-se no merengue-jazz: sua composição "Periblues", por exemplo, combina jaleos de saxofone em brasa com harmonias de blues.

O saxofonista alto e tenor Carlito Estrada frequentemente se apresenta com Mirabal. Estrada é, em minha avaliação, o expoente mais inspirado e com maior autoridade no jazz da República Dominicana hoje. Ele desenvolveu um arrojado estilo pessoal de improvisação altamente influenciado pelo tenorista Michael Brecker. Como um nativo da região do Cibao, Estrada percebe um envolvimento com o estilo merengue típico, e ocasionalmente toca com grupos de merengue centrados no acordeão. Como outros músicos dominicanos que trabalham com idiomas não-comerciais, Estrada sofre com uma carência aguda de oportunidades de gravação, sobrevivendo primariamente como músico em bandas de hotel. ${ }^{32}$

\section{Mario Rivera}

Mario Rivera nasceu na capital da República Dominicana em 1939. Na infância, tocava tambora pela casa, e na adolescência começou a tocar oboé com uma banda associada ao Corpo de Bombeiros. Logo ele mudaria para o saxofone soprano e então para o tenor, e na idade de 18 anos, juntava-se aos The Happy Boys, uma das duas únicas bandas de rock ' $n$ roll do país. Rivera logo seguiu adiante, indo trabalhar com Antonio Morel y su Orquesta, uma das melhores orquestras de dança do país; este era o grupo favorito da filha de Trujillo, Angelita, e frequentemente se apresentava em eventos que contavam com a presença do ditador. Rivera foi em frente, passando a trabalhar em La Voz Dominicana com a Orquesta Angelita (assim chamada em referência à mesma filha), liderada por Tavito Vásquez. Esta era uma banda de estúdio que acompanhava cantores na televisão; sua formação básica de cinco saxofones e

\footnotetext{
32 Também deve-se notar na cena do merengue de Santiago o guitarrista Edwin Lora, o saxofonista Sandy Gabriel, o percussionista Felle Vega e o baixista Quico del Rosario.
} 
quatro trompetes era algumas vezes aumentada com uma pequena seção de violinos, um flautista clássico, violoncelo e fagote.

Vásquez frequentemente improvisava com o grupo, e Rivera mais tarde rememorou que os solos de Vásquez foram sua “iniciação no jazz”. Rivera começou a estudar esta música, por exemplo transcrevendo o solo de Stan Getz em "Pennies from Heaven". Já neste período inicial, Rivera experimentou com o merengue, adaptando ritmos de tambora para o compasso 5/4 ao tocar junto com o sucesso de Dave Brubeck, “Take Five”, só “por diversão”, como ele me contou³ Como veremos, posteriormente em sua carreira, Rivera desenvolveu uma aguda tendência para a exploração musical multi-instrumental.

Rivera se mudou para a cidade de Nova York depois que Trujillo foi assassinado em 1961. Embora muitas gravações de jazz tenham estado disponíveis na República Dominicana durante a dominação de Trujillo, o fato de que apenas certos selos eram distribuídos então impôs uma educação musical desequilibrada. Quando Rivera chegou nos EUA, ele já estava familiarizado com Sonny Rollins, Gerry Mulligan, Stan Getz e Zoot Sims, mas nunca havia ouvido falar de Count Basie, Duke Ellingon ou Charlie Parker. Ele logo foi empregado como saxofonista barítono para a importante banda de mambo de Tito Rodriguez, passando a trabalhar por todo o país, além de fazer turnês na América do Sul de 1963 a 1966. Depois, trabalhou com Tito Puente de 1966 a 1972 e então com grupos como Machito, Eddie Palmieri e Tipica'73.

O trabalho neste ambiente evidentemente o expôs a grandes músicos de jazz, mas Rivera nunca decidiu conscientemente especializar-se em jazz: ele me disse que "apenas queria aprender o que era, porque eu gostava dele. Eu não disse 'quero ter uma carreira no jazz', não, . . . aconteceu naturalmente que o amor por ele levou-me a estar no lugar certo" ${ }^{34}$. Rivera desenvolveu uma amizade com o saxofonista tenor George Coleman e juntou-se ao Coleman's Octet, que ensaiava no apartamento de Rivera. Coleman ajudou Rivera a dominar a linguagem jazzística, e em pouco tempo ele estava tocando na United Nations

\footnotetext{
${ }^{33}$ Entrevista com Rivera / OMITIDO.

${ }^{34}$ Entrevista com Rivera / OMITIDO.
} 
Band (uma organização all-star cubop) de Dizzy Gillespie e tocando por breves períodos com nomes como Roy Haynes, Reggie Workman, Sonny Stitt e Roy Brooks.

Embora seu principal instrumento seja o saxofone tenor, Rivera também toca saxofones barítono e alto, flauta, flauta alto, trompete, vibrafones e tambora. Entre os músicos de jazz em Nova York, ele é conhecido por praticar de maneira incessante e pelas vibrantes jam sessions que mantém em seu apartamento em Manhattan na madrugada. Rivera me disse que ele começou esta voraz atividade dual "pela diversão":

Na verdade, não estou realmente praticando aqui, estou tocando, entende. Eu realmente toco mais de sete horas [por noite] em geral, sim. Posso ficar por um longo tempo com um instrumento . . ., e então fico com outro. Gosto de tocar principalmente à noite. Posso começar provavelmente às seis da tarde, ou três ou quatro da tarde, e ir até às seis da manhã do dia seguinte . . - tocando e parando, sabe, aprendendo as músicas, praticando alguns exercícios dos livros ou o que seja. Ou assistir a vídeos musicais, compreende. Para mim é tipo 24 horas, diria; eu simplesmente desenvolvi esta disciplina para ser capaz de seguir adiante ${ }^{35}$.

Como a maior parte dos músicos de jazz, Rivera possui uma abrangente quantidade de gostos:

Eu ouço rap, ouço música cubana, ouço música brasileira, ouço rock and roll também. Você entende, eu ouço tudo . . . Ouço Beethoven, Bach, . . . todos os grandes flautistas clássicos, entende, James Galway, ele é tipo meu ídolo, . .. [Jean Pierre] Rampal. Tudo é música, cara $^{36}$.

Como foi mencionado, Rivera tocou tambora por anos, e à medida que ele se envolvia com o jazz ele passou a ver "que a tambora tinha possibilidades de ser um instrumento virtuoso como a conga ou timbales" ${ }^{37}$.Rivera, na verdade, tocou tanto tambora quanto madeiras com Dizzy Gillespie em turnê na Europa,

\footnotetext{
${ }^{35}$ Entrevista com Rivera / OMITIDO.

${ }^{36}$ Entrevista com Rivera / OMITIDO.

${ }^{37}$ Entrevista com Rivera / OMITIDO.
} 
como foi documentado no CD dos vencedores do Grammy Award, Live at Royal Festival Hall ${ }^{38}$.

Em meados dos anos 80, um grupo de músicos latinos em Nova York, liderados pelo trompetista/conguero Jerry González e com a participação de seu irmão, o baixista Andy González, começou a desenvolver um repertório de jazz latino e a apresentar jam-sessions informais nos clubes de jazz Nuyorican Village e Soundscape. Estes músicos trabalharam em várias configurações, com vários líderes. Rivera foi parte desta cena e começou seu próprio grupo de jazz latino chamado Salsa Refugees. Ele explicou para mim que embora possa parecer que o nome se refira a assuntos de imigração, ele na verdade diz respeito ao desejo dos músicos de deixar de lado a salsa comercial para desenvolver novos modos musicais: o nome "soa como um nome político, mas . . nós [apenas] queríamos tocar uma música mais criativa em vez de ter que tocar salsa" 39.

O Mariel boatlift (êxodo Mariel, movimento de partida em massa dos cubanos no ano de 1980 do porto cubano de Mariel em direção aos EUA, N.T.) trouxe muitos músicos cubanos excelentes aos Estados Unidos, incluindo o saxofonista / clarinetista Paquito d'Rivera e o conguero Daniel Ponce. Sua presença modificou o clima do cenário do jazz latino em Nova York, e foi nessa atmosfera que Rivera tornou-se mais interessado em desenvolver ritmos dominicanos em vez de cubanos. Ele me disse que

existe tipo [um pouco de] fricção entre os cubanos e os porto-riquenhos a respeito da música . . . [então] eu disse, não, eu não quero brigar por causa de música. Eu sou dominicano, então vou . . . [desenvolver] o merenguejazz. ${ }^{40}$

Destacando músicos estabelecidos de jazz latino como o trombonista Steve Turré e o pianista Hilton Ruiz e trabalhando primariamente na cidade de Nova York, os Salsa Refugees tocavam ritmos cubanos e brasileiros mas sua contribuição

\footnotetext{
${ }^{38}$ CD Gillespie.

${ }^{39}$ Entrevista com Rivera / OMITIDO.

${ }^{40}$ Entrevista com Rivera / OMITIDO.
} 
mais original era o uso de ritmos dominicanos; Rivera acreditava que "a tambora e a güira acrescentam . . . cores diferentes" ${ }^{41}$. Seus percussionistas Julito Figueroa, Chinito Díaz e Isidro Bobadilla instigaram experimentos rítmicos, usando combinações não convencionais como duas tamboras e conga. Quando Figueroa se juntou ao grupo, ele queria tocar congas, mas Rivera pediu a ele para tocar também a tambora. Figueroa levou a sério o conselho de Rivera, desenvolvendo um estilo único de tocar tambora como uma arte de improvisar em solo. Ele continua a desenvolver este idioma hoje na República Dominicana a despeito da escassez de espaços para se apresentar ${ }^{42}$.

Bobadilla, que mais tarde se tornou um membro regular da banda de Juan Luis Guerra, havia estudado percussão afro-dominicana com o folclorista Fradique Lizardo. Ele trouxe para o grupo os tambores chamados palos, que são usualmente empregados em cerimônias religiosas afro-dominicanas, utilizando três palos em arranjos de músicas como "Equinox" e "Spiritual". Rivera explicou-me que ele havia sido exposto aos palos quando criança. Como vimos, muitos dominicanos evitam falar abertamente sobre práticas religiosas afroderivadas. Rivera, entretanto, não possui tais escrúpulos; é provável que sua prolongada participação na cena musical afro-cubana de Nova York tenha influenciado sua atitude. Rivera me disse que sua avó era uma curandeira tradicional devota de "Dolorita", a Virgen de Dolores, uma santa sincretizada com o espírito afrodominicano Metresili³. Sua avó o levava a cerimônias nas quais os palos eram executados:

[M]inha avó era como um médico rural [que] costumava preparar remédios . . . [E]les trouxeram aquela santa, aquela Dolorita . . . em uma procissão . . . Eu vi aquilo quando criança . . . Eu costumava ir e ouvir e ficávamos acordados a noite toda e eles ficavam cantando todos aqueles cantos e . . . tocando os palos ${ }^{44}$.

\footnotetext{
${ }^{41}$ Entrevista com Rivera / OMITIDO.

${ }^{42}$ Pode-se ouvir a execução de Figueroa no CD OMITIDO 1997b.

${ }^{43}$ Metresili é o mesmo que o Iwa (ou espírito) vudu haitiano Metres Ezili.

${ }^{44}$ Entrevista com Rivera / OMITIDO.
} 
Durante os anos 80 e 90, Rivera foi músico regular do Latin Jazz Ensemble de Tito Puente, um pequeno grupo que requisitava as competências de Rivera como solista de jazz; o primeiro LP deste grupo, On Broadway, ganhou um Grammy e destaca Rivera tocando uma versão latina e ritmicamente inovadora de "Sophisticated Lady". O trabalho continuado com Puente deixou a Rivera pouco tempo para dedicar aos seus projetos de merengue-jazz. Em 1994, no entanto, Rivera gravou um CD chamado El Comandante... the Merengue-Jazz, que trazia o tenorista George Coleman e o baixista Walter Booker junto com Rivera, o pianista Hilton Ruiz e uma seção de percussão dominicana em uma gravação que documenta a marca da experimentação que ele havia começado com os Salsa Refugees. O CD inclui straight-ahead bebop, merengue-jazz e arranjos que alternam de maneira fluida entre ritmos de bebop e merengue. $\mathrm{O}$ uso prodigioso, por parte de Rivera, de colcheias em tempo dobrado, parte integral tanto do bebop quanto do merengue, está igualmente enraizado em ambas tradições (Rivera, 1994).

\section{Contradição e criatividade}

Durante os anos 80 e 90 muitos músicos dominicanos e observadores da cultura lamentaram a falta de exposição de Tavito Vásquez e seu isolamento do centro dos acontecimentos jazzísticos; este mestre da música dominicana nunca recebeu o reconhecimento que merece. Para tornar as coisas piores, havia poucos, se algum, músicos de jazz do seu calibre vivendo na República Dominicana, portanto Vásquez carecia agudamente de colaboradores musicais.

Objetivando pagar um tributo a este inovador do jazz dominicano, Mario Rivera colocou Vásquez junto com músicos de jazz do primeiro time da cidade de Nova York para realizar uma gravação. Embora nunca tenha sido lançada, a sessão de gravação produziu música excelente, consistindo de standards de merengue executados com arranjos jazzísticos. Aqui, além de seus solos seguros no saxofone tenor, Mario Rivera demonstra seu domínio técnico e inventividade jazzística no trompete e vibrafones. Embora evidencie a espontaneidade de uma performance 
ao vivo - a maior parte das faixas foram feitas em apenas um take - a gravação também destaca as gravações de Rivera de jaleos em overdub para cinco saxofones, que evocam o som de saxofone inspirado no acordeão, uma inovação da Orquesta Hermanos Vásquez tornada famosa pelas big bands de merengue dos anos 50 .

Combinada com o sotaque típico da seção de percussão inteiramente dominicana, esta gravação de jazz está firmemente enraizada no merengue tradicional. Vásquez brilha na companhia de músicos que partilham sua sofisticação musical, e executando solos mais prolongados do que em gravações anteriores. Mergulhando em seus vôos reminiscentes de Charlie Parker, tríades diatônicas deslocadas e esquemas em escalas diminutas, sua imaginação musical está tão relaxada e criativa quanto estava com grupos centrados no acordeão, exceto que em vez de uma harmonia estática e uma textura dominada pelo acordeão, o saxofone é banhado por timbres de piano, baixo e percussão e suportado por harmonias jazzísticas variantes. Esta gravação ocorreu nos últimos dias de Vásquez, antes de sua morte em 1995. Os músicos dominicanos lamentam seu trágico falecimento na pobreza e obscuridade.

O médico dominicano Federico Chan é amigo e admirador de longa data de Tavito Vásquez e Mario Rivera é um promotor e mecenas autônomo de jazz dominicano. Seus esforços para promover a música incluem a produção do CD colaborativo com Rivera/Vásquez com seus próprios recursos. Chan contou-me a respeito de suas motivações:

O merengue possui valor cultural. É a coisa dominicana mais autêntica, exatamente como o jazz é a mais autêntica contribuição estadunidense às artes. Nós [dominicanos] não possuímos um pintor, poeta ou novelista do nível do [autor colombiano] Gabriel García Marquez, mas temos estes merengues" 45 .

Os esforços de Chan para agendar o grupo de Rivera/Vásquez no prestigioso Teatro Nacional da República Dominicana não tiveram sucesso. Ele

\footnotetext{
${ }^{45}$ Chan, comunicação pessoal ao autor.
} 
acredita que o foco do grupo no merengue está por trás da rejeição; o Teatro Nacional costumeiramente apresenta sinfonias e concertos, não formas locais afrocaribenhas. Ressaltando que a performance neste espaço de prestígio teria significado muito para Tavito Vásquez, ele não escondeu sua amargura quando contou-me que "os pseudo-intelectuais da República Dominicana ainda rejeitam o merengue".

O pianista Michel Camilo (também conhecido como Michael Camilo) emergiu como o músico dominicano de jazz mais bem sucedido de todos os tempos nos anos 80 e 90. Camilo estudou música clássica no Conservatório Nacional Dominicano em sua juventude e tocou com a Orquestra Sinfônica Nacional Dominicana já com dezesseis anos. Camilo desenvolveu amor pelo jazz desde tenra idade e mudou-se para a cidade de Nova York em 1979 para aprimorar-se nesta música. Depois de alguns anos ele se tornou um membro regular da banda do saxofonista e clarinetista cubano Paquito d'Rivera.

Além de tornar-se procurado por seu comando virtuosístico do piano, Camilo ficou famoso pela originalidade de suas composições. Enquanto a maior parte do jazz latino está baseada em ritmos cubanos e experimentadores como Tavito Vásquez e Mario Rivera fundem merengue com jazz, Camilo desenvolveu um estilo polido e idiossincrático que combina ritmos e melodias que soam genericamente latinas com jazz e funk em músicas efervescentes que ficam na memória. Paquito D’Rivera usou a composição de Camilo “Why Not!” como a música-título de um de seus álbuns, e sua subsequente gravação pelo Manhattan Transfer ganhou um Grammy em 1983 (Camilo, 1992). Baseado na cidade de Nova York, Camilo faz frequentes visitas ao seu país natal, onde seus compatriotas são justificavelmente orgulhosos de suas conquistas; ele foi até mesmo condecorado como "Cavaleiro da Ordem Heráldica de Cristóvão Colombo" pelo governo dominicano em 1992. No ano seguinte, Camilo foi convidado a tocar o Piano Concerto em Fá Maior de Gershwin com a Orquestra Sinfônica Nacional Dominicana no prestigioso Teatro Nacional ${ }^{46}$.

\footnotetext{
${ }^{46}$ Anônimo b.
} 
Dominicanos jovens começaram a questionar o eurocentrismo tradicional de seu país durante a era pós-Trujillo. Enquanto muitos moradores urbanos associavam a percussão e religião afro-dominicanas com estilos de vida ultrapassados, outros, especialmente artistas e intelectuais, abraçaram a filosofia de que "o negro é lindo" (Del Castillo e Murphy, 1987-88, p. 62). A questão da origem do merengue foi central para um debate que se desenvolveu entre dominicanos conservadores, que insistiam na identidade hispânica da República, e aqueles que promoviam a herança africana do país. A facção de mentalidade tradicional reivindicou que o merengue possuía pouca ou nenhuma influência africana, enquanto os pensadores progressistas celebrava sua estética afroderivada. O bandleader Juan Luis Guerra falou eloquentemente sobre as raízes africanas do merengue sem negar sua natureza sincrética: “Inequivocamente, não se pode separar o merengue da África. Não importa o quanto você possa desejálo, não se pode retirá-lo da África. Esqueça: os ritmos são africanos e ponto final. É claro que há estas influências, que são melódicas: as melodias são europeias, a harmonia, exatamente como no jazz" ${ }^{47}$.

Muitos jovens urbanos, cujos antepassados haviam deixado de lado o interior dominicano e as artes tradicionais, juntaram-se a grupos de dança folclórica que executavam versões estilizadas de dança e percussão ritual afrodominicana. Jovens artistas formaram bandas que misturaram percussão afrodominicana com estilos não-dominicanos que iam de música peruana ao rock e jazz. Os violonistas/compositores Luis Días e Tony Vicioso e cantores José Duluc e Xiomara Fortuna tomaram a frente deste movimento musical ${ }^{48}$. Vicioso me disse que como a maioria dos latino-americanos de classe média, seus primeiros amores musicais foram o rock e o jazz. Entretanto, um dia, ouvindo McCoy Tyner enquanto dirigia no interior da República Dominicana, ele encontrou uma banda de músicos e dançarinos executando a música de procissão para trompetes e percussão chamada gagá. Vicioso imediatamente conectou a música afroamericana que estava tocando em seu carro à expressão afro-dominicana viva que

\footnotetext{
${ }^{47}$ Entrevista com Guerra / OMITIDO.

${ }^{48}$ ver a gravação Various artists.
} 
o cercou. Depois de estudar jazz nos Estados Unidos, Vicioso percebeu que, como ele me disse, "havia uma coisa dominicana na qual eu precisava entrar". Retornando à República, ele começou a fazer trabalho de campo sobre percussão afro-dominicana e a compor música que combinava percussão dominicana com jazz. Mas como ele diz, "existe uma resistência” à percussão afro-dominicana na República; “as pessoas não apreciavam este tipo de coisa"49. Desde 1991, Vicioso vem tocando e realizando oficinas educacionais sobre cultura afro-dominicana em escolas públicas da cidade de Nova York.

Apesar de suas composições serem inconfundivelmente afro-caribenhas, a formação clássica de Michel Camilo e seu sucesso nos palcos internacionais tornam suas músicas concordantes com a eurofilia dominicana; Camilo é saudado como um tesouro nacional na República. Já Tavito Vásquez, por outro lado, nunca recebeu o reconhecimento que merece; seu passado como músico de merengue da classe trabalhadora conflita com noções convencionais dominicanas de "alta cultura".

Ao mesmo tempo, o estatuto do merengue como símbolo nacional e o fato de haver-se desassociado dos rituais religiosos afro-dominicanos dão-lhe mais reconhecimento do que o usufruído pela percussão ritual afro-dominicana; em forte contraste com a celebração midiática que cerca o merengue pop, gêneros como palos, salve e gagá e artistas como José Duluc e Tony Vicioso não possuem nenhum acesso à indústria musical dominicana. É irônico que as classes dominantes na República Dominicana, que frequentemente buscam conexões cosmopolitas, estejam tão desligadas do movimento pan-africano transnacional. Embora haja uma próspera indústria musical na República Dominicana, esta indústria promove apenas o merengue comercial, negligenciando tanto a música religiosa tradicional afro-dominicana quando experimentos audaciosos no jazz dominicano e na música popular experimental.

\footnotetext{
${ }^{49}$ Entrevista com Vicioso / OMITIDO.
} 
Como uma música afro-americana, o jazz presentifica uma alternativa aos elementos hegemônicos e euro-estadunidenses nos EUA. Ao mesmo tempo, o jazz representa conexões com a hegemonia estadunidense nas mentes de muitos aficionados dominicanos, que o veem como uma marca cosmopolita de status social. Por outro lado, músicos dominicanos criaram híbridos de merengue-jazz esteticamente integrados que se apresentam como uma afirmação das fundações compartilhadas das músicas de influência africana nas Américas.

\section{Referências}

ALBERTI, Luis. De música y orquestas bailables dominicanas, 1910-1959. SantoDomingo: Taller, 1975.

ANÔNIMO. “Nació el jazz en Santo Domingo?” Listín Diario. March 26, 1931.

ANÔNIMO. Sem data A. "Michel Camilo", release de imprensa. Sem data.

CALDER, Bruce. The Impact of Intervention: The Dominican Republic during the U.S. Occupation of 1916-1924. Austin: University of Texas Press, 1984.

COPLAN, David B. In Township Tonight! South Africa's Black City Music and Theater. London: Longman, 1985.

CRASSWEILER, Robert D. Trujillo: Life and Times of a Caribbean Dictator. New York: MacMillan, 1966.

DAVIS, Martha Ellen. Afro-Dominican Brotherhoods: Structure, Ritual, Music. 1976. (Tese de doutorado)-University of Illinois, Illinois, 1976.

- Vozes del purgatorio: estudio de la salve dominicana. Santo Domingo: Ediciones Museo del Hombre, 1981.

DEL CASTILLO; MURPHY. Migration, National Identity, and Cultural Policy in the Dominican Republic. Journal of Ethnic Studies 15/3, p. 49-69, 1987-88.

FANON, Frantz. Black Skin, White Masks. New York: Grove Press, [1952] 1967.

FERNÁNDEZ SOTO, Carlos and Edis Sánchez. Los Congos de Villa Mella. Latin American Music Review 18/2, p. 297-316, 1997.

HERNÁNDEZ, Julio A. Música tradicional dominicana. Santo Domingo: Julio D. Postigo, S. por A., 1969.

HERSKOVITS, Melville. Life in a Haitian Valley. New York: A.A. Knopf, 1937.

HOETINK, H. The Dominican people 1850-1900: notes for a historical sociology. Baltimore: Johns Hopkins University Press, 1982.

INCHÁUSTEGUI, Arístides. Luis Alberti (1906). Listín Diario 27 Marzo, p. 24. 1973. 
p. 20, 1974.

. Juan Bautista Espínola Reyes (1894-1923). Listín Diario 29, Septiembre,

MCLANE, Daisanne. Dance-Till-You-Drop Merengue. New York Times, 6 January, p. 28, 38, 1991.

PACINI HERNANDEZ, Deborah. Bachata: a social history of a Dominican popular music. Philadephia: Temple University Press, 1995.

PÉREZ-CABRAL, Pedro Andrés. La comunidad mulata. Caracas: Gráfica Americana, 1967.

RIVERA GONZÁLEZ, Luis. Antología musical de la era de Trujillo 1930-1960. Ciudad Trujillo: Publicaciones de la Secretaria de Estado de Educación y Bellas Artes, 1960.

RODRÍGUEZ DEMORIZI, Emilio. Música y baile en Santo Domingo. Santo Domingo: Colección Pensamiento, 1971.

SOLANO, Rafael. Letra y música: Relatos autobiográficos de un músico dominicano. Santo Domingo: Taller, 1992.

TEJEDA, Darío. La historia escondida de Juan Luis Guerra y los 4:40. Santo Domingo. Ediciones MSC, Amigos del Hogar, 1993.

TURINO, Thomas. Nationalists, Cosmopolitans, and Popular Music in Zimbabwe. Chicago: University of Chicago Press, 2000.

\section{Entrevistas concedidas ao Autor}

GUERRA, Juan Luis (bandleader); Santo Domingo, República Dominicana, 1985.

HERNÁNDEZ, Julio Alberto (compositor). Santo Domingo, República Dominicana, 1985.

INCHÁUSTEGUI, Arístides (historiador da música e cantor); Santo Domingo, República Dominicana, 1985.

LORA, Antonio (acordeonista). Santiago, República Dominicana, 1985.

MATEO, Joseíto (cantor). Santo Domingo, República Dominicana, 1985.

PICHARDO, Agustín (dançarino de merengue e conhecedor). Santiago, República Dominicana, 1985.

RIVERA, Mario (multi-instrumentista). New York, NY, 2001.

TOLENTINO, Pavín (bandleader). Santiago, República Dominicana, 1985.

VÁSQUEZ, Tavito (saxofonista). Santo Domingo, República Dominicana, 1985.

VICIOSO, Tony (guitarrista e bandleader). New York, 1994. 


\section{Discografia}

OMITIDO

CAMILO, Michel. Why not? Evidence ECD 22002-2, 1992.

DE LEÓN, Choco. San Cristóbal: Merengues Instrumental (sic). Quisqueya, 1981.

GILLESPIE, Dizzy. Dizzy Gillespie and his Big Band in Concert, featuring Chano Pozo. GNP/Crescendo GNPD 23, 1993.

GUERRA, Juan Luis and 4:40. El Original 4:40. Wea Latina (sem numeração), [1984] 1991.

RIVERA, Mario. “El Comandante” -the Merengue-Jazz. Groovin' High 1011-2, 1994.

VÁSQUEZ, Tavito. Merengues Instrumentales. [fita cassette; sem selo, sem numeração]. 